REVISTA INNOVA ITFIP, 7 (1). 58-77. DIC. 2020

\title{
ANÁLISIS DE PERCEPCIÓN DEL NEGOCIO COMPRA DE CARTERA EN GERENTES Y CLIENTES DE LOS BANCOS COMERCIALES EN LA CIUDAD DE NEIV A
}

\section{BUSINESS PERCEPTION ANALYSIS OF PORTFOLIO PURCHASE IN MANAGERS AND CUSTOMERS OF COMMERCIAL BANKS IN THE CITY OF NEIVA}

\author{
Carlos Francisco Tello Perdomo ${ }^{1}$ \\ Catherine Ramírez Hernández ${ }^{2}$ \\ Andrés Felipe Franco Martínez ${ }^{3}$
}

Cómo citar esté artículo: Tello Perdomo, C. F., Ramírez Hernández, C., Franco Martínez, A. F. (2020). Análisis de percepción del negocio compra de cartera en gerentes y clientes de los bancos comerciales en la ciudad de Neiva. Revista Innova ITFIP, 7(1), 58-77

Recibido: Mayo de 2020. Aprobado: Diciembre de 2020

DOI: $10.13140 / \mathrm{RG} .2 .2 .23349 .91366$

\section{Resumen}

En la ciudad de Neiva se aplica la oferta como a nivel nacional del servicio de crédito de libre inversión "Compra de cartera", donde se otorgan con el propósito de dar liberación de efectivo y obtener nuevos márgenes de liquidez; lo que se pensaba ser una solución hoy se vinculan excesivos de cobros y perjuicios desde la dinámica de recaudo. El sistema de asesoría y la forma rápida de acceder a ellos es la base del problema; con dificultades los clientes manejan los flujos de caja y como los gerentes bancarios inclusive asesoran para mejorar los flujos de efectivo para alcanzar a cubrir nuevos pasivos financieros, el fin de su creación no era para seguir creciendo en deuda; sino por el contrario, darle dinamismo a la economía en la liquidez del cliente.

La investigación se desarrolló en 4 entidades bancarias en Neiva y se realizó con la muestra de 350 clientes que han accedido al negocio. Se justifica la investigación porque es preciso

\footnotetext{
${ }^{1}$ Administrador Bancario y Financiero, Psicólogo, Especialista en Gerencia de las Organizaciones de la Salud, Maestrante en Administración de Organizaciones. Profesional Investigador del Grupo CORAT ENEA de la Corporación Universitaria del Huila. carlos.tello@corhuila.edu.co

${ }^{2}$ Profesional Universitario Administrador Bancario y Financiero de la Corporación Universitaria del Huila, con experiencia en el Sistema Financiero Colombiano; con más de 8 años en establecimiento de Crédito en la Ciudad de Neiva, pasando por Davivienda y actualmente trabajando para el Banco Popular en la Ciudad de Neiva. catherin.ramirez06@gmail.com

${ }_{3}^{3}$ Profesional Universitario Administrador Bancario y Financiero de la Corporación Universitaria del Huila, con experiencia en el Sistema Financiero Colombiano; con más de 5 años en establecimiento de Crédito en la Ciudad de Neiva; actualmente cursando un Master en Francia con integración en Alemania en Banca, Moneda y Seguros Internacional. andresfelipefrancomartinez1993@gmail.com
} 
establecer las bondades y desventajas de este sistema, y responsabilidades financieras de quienes están en este nuevo proceso. Como objetivo general, analizar la percepción del negocio compra de cartera en gerentes y clientes de los bancos comerciales en la ciudad de Neiva; y específicos: primero, describir la posición de los gerentes frente al negocio de la colocación de recursos financieros con el portafolio "Compra de Cartera"; segundo, identificar las variables que deben distinguir los clientes para una adecuada toma de decisiones a la hora de adquirir créditos en esa modalidad; y tercero, generar la relación de beneficios y riesgos a las que se exponen gerentes y clientes de bancos en dicho negocio. Como fin último se estableció que las gerencias, los directores, asesores han llevado a entregar los diferentes portafolios con libertades que inclusive los mismos clientes no midieron; las gerencias canalizaron asesorías que incrementaron eventos inflacionarios por liberación de efectivo.

Palabras clave: Producto Bancario, Colocación, Captación, Obligación Bancaria, Venta de Crédito, Compra de Cartera

\begin{abstract}
In the city of Neiva, the offer is applied as at the national level of the free investment credit service "Portfolio purchase", where they are granted with the purpose of releasing cash and obtaining new liquidity margins; What was thought to be a solution today is linked to excessive charges and damages from the collection dynamics. The advisory system and the quick way to access them is the basis of the problem; With difficulties, clients manage cash flows and as bank managers even advise to improve cash flows to cover new financial liabilities, the purpose of its creation was not to continue growing in debt; but on the contrary, give dynamism to the economy in the liquidity of the client. The research was carried out in 4 banking entities in Neiva and it was carried out with a sample of 350 clients who have accessed the business. The investigation is justified because it is necessary to establish the advantages and disadvantages of this system, and financial responsibilities of those- who are in this new process. As a general objective, to analyze the perception of the portfolio purchase business in managers and clients of commercial banks in the city of Neiva; and specific: first, to describe the position of the managers in the business of the placement of financial resources with the portfolio "Portfolio Purchase"; second, to identify the variables that clients must distinguish for adequate decision-making when acquiring credits in this modality; and third, to generate the relationship of benefits and risks to which bank managers and clients are exposed in said business. As an ultimate goal, it was established that the managements, directors, advisers have led to the delivery of the different portfolios with freedoms that even the clients themselves did not measure; The managements channeled advice that increased inflationary events due to the release of cash.
\end{abstract}

Keywords: Banking Product, Placement, Funding, Bank Obligation, Sale of Credit, Purchase of Portfolio 


\section{Introducción}

En Colombia se viene adelantando situaciones de regulación de tasas de interés, por los mismos factores y comportamientos de mercado con relación al gasto y la erogación reflejada en la inflación; también existen situaciones externas como lo es la vía del apalancamiento financiero o de encontrar liquidez para respaldar inclusive sus inversiones, otros en el peor de los casos pretenden saldar nuevas o antiguas obligaciones. Para encontrar el cubrimiento ante las necesidades económicas de terceros e incluso de la misma entidad financiera buscan una salida a la generación de liquidez para obtener "solvencia" y tratar de oxigenar la vida económica, unos logran realizar ejercicios mercantiles como invertir para obtener beneficios económicos futuros, pero otros lo que hacen es crear flujo de caja para gastar más. Con tal oportunidad los bancos, las entidades financieras en especial los llamados establecimientos de crédito como bancos han diseñado un portafolio para personas naturales y jurídicas que desean capitalizarse, de apalancarse; siempre prestos en las oportunidades para mejorar la dinámica financiera sobre el circulante, sobre la inversión, sobre el activo mismo.

Las trasformaciones comerciales buscan mejorar en las ventajas competitivas de unos comerciantes con respecto a los más débiles financieramente hablando; de hecho, las políticas financieras hoy desarrolladas por muchos pensadores y analistas han fijado prontamente y con oportunidad de mejora sobre su organización las medidas de centralizar sus compromisos y ejercer control sobre los recursos a tasas más exequibles. Se evidencia que las personas indudablemente desean mejorar su nivel de liquidez inclusive con sus propios niveles de ingresos en la base de un flujo de caja; unas buscadas sobre su mismo desarrollo mercantil ofertando y otros haciendo descuentos con la posibilidad de tener soluciones financieras y como no siempre se logra el objetivo, entonces buscan el apoyo financiero con otras entidades de tipo financiero en pro de mejorar en materia de inversión.

Del mismo modo, como también han buscado el progreso ambicioso a muchos niveles por delante de la incertidumbre financiera; creen encontrar el camino a la solución de sus problemas en el apalancamiento financiero, en el endeudamiento, en el empezar con carteras que mitigaran quizás el riesgo de sus finanzas. Las entidades financieras en medio de su portafolio de servicios de igual forma buscan ser competitivas y por ello ofertan la llamada línea de crédito de libre inversión "compra de cartera" para incrementar sus ingresos como también dar "cash flow" a quienes les prestan.

Unas ventajas sobre incurrir a la deuda puedan ser encontradas con oportunidades en desde este negocio; en hora buena, también los puede hacer llegar a un éxito financiero. Se hace referencia a estos casos cuando la posibilidad de tener la forma de apalancamiento cubre y producen para el cumplimiento de obligaciones y hacer posibles futuras nuevas inversiones. La compra de cartera 
REVISTA INNOVA ITFIP, 7 (1). 58-77. DIC. 2020

ha sido la forma de negociar hoy en día no solo para aquellas personas naturales sino también jurídicas al procurar mejorar los niveles de liquidez en el logro de estar al día con varios acreedores

en sus compromisos, y dejar la deuda con una sola entidad. En dichos aspectos no todo es fijado de manera ideal, muchos de los beneficiados también han incurrido a la mala utilización donde inclusive estos bancos les ha quedado la tarea de recuperar carteras de este mismo portafolio que lograron desembolsarles, que en ciertos en casos ya están en cobros conciliatorios, otros con cobros coactivos, y hasta embargos.

El trabajo se fundamentará en el amplio conocimiento del servicio ofertado por las entidades financieras legalmente constituidas para hacer efectiva la captación y colocación de los recursos del público en lo que tiene que ver con lo denominado "compra de cartera" que en realidad no es otra cosa que un crédito de libre inversión a tasas más bajas en el mercado financiero como portafolio activo. El ejercicio se ha hecho tan frecuente que las entidades financieras con el afán de vender promueven en sus servicios comerciales un producto el cual es demandado por los antiguos y nuevos clientes en la premura de cubrir obligaciones diversas, las cuales fueron abiertas por que su capacidad de pago lo permite; los créditos otorgados por estas entidades a quienes son beneficiados "producen estados de confort por la deuda a cubrir debido a su baja tasa"; esos compromisos que dejan en manos de una sola entidad lo que hacen es trasladar en ocasiones la responsabilidad en créditos que le vinculan a una tasa más baja como se expresó anteriormente, pero que en el tiempo se extiende a nuevos plazos para pagar dichos compromisos en un mayor plazo si así lo desea el cliente, repercutiendo sobre la amortización del mismo.

\section{Marco teórico}

La compra de cartera consiste en trasladar un saldo parcial o total de una entidad financiera a otra que le puede ofrecer una mejor tasa de interés y extenderle el plazo del pago de sus obligaciones. El usuario debe acercarse a una entidad financiera o en la misma donde está pendiente el saldo y solicitar la compra de cartera; dependiendo de la actividad laboral, usted deberá cumplir con algunos requisitos como, por ejemplo, si es independiente: deberá presentar declaración de renta o RUT, extractos bancarios, cámara de comercio y fotocopia de la cédula.

\section{La compra de cartera le conviene}

Cada vez es más común que para aumentar su participación en el mercado, los bancos utilicen la estrategia de comprar cartera de su competencia. Compran todo, desde créditos hipotecarios, de vehículos, de libranzas y de tarjetas de crédito. Los bancos perciben esta opción como una forma segura de quedarse con clientes que tengan créditos vigentes con el sistema y que además, cuenten con un buen historial crediticio ${ }^{1}$. A su vez, las entidades les ofrecen la compra de

\footnotetext{
${ }^{1}$ http://www.finanzaspersonales.com.co/invierta-a-la-fija/articulo/la-compra-de-cartera-le-conviene/37133
} 
REVISTA INNOVA ITFIP, 7 (1). 58-77. DIC. 2020

cartera a los clientes como una forma de unificar las deudas y bajar sus tasas de interés. Por lo general, las tasas que ofrecen son menores que las que la persona pactó cuando adquirió su tarjeta de crédito. (Personal, 2017)

En todos los aspectos pueden entonces lucir ventajas y desventajas de un lodo como de otro por lo tanto la precisión esta mercada en el manejo de la información por los diferentes actores, y además lo que hace que la actividad favorezca o desfavorezca para unos y a otros pueden ser generados por la competencia misma en los diferentes tipos de tasas que ellas las amparan, y así lo hace ver en los estado comparativos de los establecimiento de crédito de las cuentas de ahorro, en el manejo de tarjetas de crédito. (Superfinanciera, 2018)

Son las entidades financieras en especial los bancos las que vienen ofertando tasas que al parecer favorecen en la compra de cartera y le informan que puede existir formas en la que pueden acceder al ahorro, dan información rápida donde los convencen y los persuaden inclusive afirman que usted puede organizar el flujo de caja y son las entidades bancarias las que perciben esta opción como una forma segura de quedarse con los clientes que inclusive tengan créditos vigentes con el sistema y que además, cuentan con un buen historial crediticio. Estas a su vez, le ofertan la compra de su deuda como una alternativa de unir las deudas y bajar las tasas de interés, menores inclusive las del mismo banco que cuando adquirió con ellos mismos las tarjetas de crédito.

\section{Cuantificación del riesgo de incumplimiento}

El estudio del riesgo de crédito como un objetivo de regulación bancaria moderna, parte de la teoría económica hasta llegar a una aproximación cuantitativa concreta. Para el caso estudio en este sentido, se plantean 2 modelos econométricos para una institución bancaria representativa en la cartera de libre inversión en el municipio de Popayán, Departamento del Cauca (Colombia), con los cuales se logra demostrar que su cartera de libre inversión es de bajo riesgo, aun bajo ciertas características del acreditado y del contrato de crédito, y por otro lado, que el riesgo de incumplimiento es elástico o altamente sensible ante el ciclo económico, e inelástico ante las tasas de interés y desempleo de la ciudad.

\section{Elementos epistemológicos sobre el riesgo crediticio}

"El riesgo de crédito puede enfocarse desde las múltiples vertientes teóricas de la disciplina económica. Una primera aproximación se encuentra en los planteamientos de Smith (1776), para quien "el tipo de interés corriente más bajo debe ser algo más que suficiente para compensar las pérdidas ocasionales a las que los préstamos, incluso con la prudencia aceptable, están expuestos (...)" (Smith, 1776, p. 178). Aunque Smith acierta al indicar que el riesgo debe compensarse con una tasa de interés, solo lo hace de manera tangencial, mientras que con los perfeccionamientos de la teoría del valor de los "nuevos clásicos" la explicación del riesgo de alguna forma pierde relevancia, dándose prioridad, como lo muestran Landreth y Colander (2006), a los avances en la teoría del interés por parte de Senior, Böhm-Bawerk y Fisher. 
Desde la visión tradicional típica de la microeconomía neoclásica heredada de Marshall, no existiría riesgo de crédito; en otras palabras, no hay lugar a pérdidas de largo plazo si se asumen los supuestos de competencia perfecta. Si bien los modelos aplicados en finanzas para la toma de decisiones de inversión utilizan los fundamentos de la teoría del consumidor neoclásica, como son las curvas de utilidad en contextos de incertidumbre, la categoría "riesgo de crédito" no tiene explicación de fondo. De hecho, los bancos son agentes "redundantes" en el modelo ortodoxo según Freixas y Rochet (1997). No obstante, de acuerdo con Idrobo (2004), tal perspectiva tiene validez (del lado del decisor empresarial) en tanto "refleja para cada individuo, la relación entre ciertas sumas de dinero (ganancia, pérdida, flujo de fondo, valor presente de un flujo de fondos u otra magnitud) y las preferencias de aquel frente al riesgo" (Idrobo, 2004, p. 10). Con excepción de tal enfoque, la teoría económica ortodoxa no aborda el riesgo, y menos en el contexto del crédito; solo se generarían pérdidas para las firmas (bancos) como consecuencia de la inflexibilidad en su estructura de costos, situación en la cual sufrirían un "efecto expulsión" de la industria (sector financiero), que de ningún modo sería desfavorable al existir la posibilidad de incorporarse a otro sector productivo, considerando la libre entrada y salida de firmas, y la perfecta sustituibilidad de factores. Por otro lado, si se habla de un escenario de competencia no perfecta, las pérdidas bancarias surgirían de las estrategias de juego de las firmas (funciones de reacción) o de su total incapacidad para coludir con otras entidades de crédito Monti (1972) y Klein (1971) demuestran cómo el volumen de créditos, y por ende la sostenibilidad bancaria, dependen del poder de mercado medido por el índice de Lerner y la elasticidad de la demanda (en monopolio), y de estos parámetros más el número de firmas (en oligopolio)."

\section{Relación de Compra de Cartera con Créditos de Libre Inversión}

El diario colombiano denominado "Portafolio" es un medio de información dentro de los cuales experto hacen referencia sobre el tema en particular e ilustran Lo que debe tener en cuenta al solicitar una compra de cartera y además indican como este método se ha convertido en uno de los más elegidos para saldar las deudas. Se hace referencia a esta actividad con el propósito de conocer qué es y cuándo debe acceder a esta línea de crédito y plantear junto con la entidad bancaria el número de cuotas y las sumas que su flujo de caja le permiten para solventar la deuda. Es una línea de crédito de libre inversión donde la persona recurrente para el caso de los beneficiarios accede para saldar sus deudas o parte de ellas, logrando en muchos casos mejorar niveles de liquidez previo análisis de los flujos de caja de cada cliente. (Portafolio, Lo que debe tener en cuenta al solicitar una compra de cartera, 2017).

\section{Metodología}

Investigación de tipo descriptivo, enfoque cualitativo, diseño longitudinal que permite la percepción de los clientes con respecto al negocio compra de cartera. El diseño de la misma se trazó con un trabajo en campo del apoyo de los gerentes de la banca en el municipio de Neiva en los que ofertan dentro de su portafolio la línea de crédito "Compra de cartera. La técnica de 
recolección de datos utilizada fue con la herramienta encuesta semi estructurada, y entrevistas a cuatro (4) gerencias de bancos donde participan con el portafolio "compra de cartera", del mismo modo la técnica documental y análisis de dato fue desde aspectos reflexivos de los antecedentes y del resultado de la aplicación de la encuestas fue sobre los clientes que han accedido a las línea de crédito, desde la base de datos suministrada por una de las entidades financieras que aportaron dicha la estándar facilitada fueron 350 clientes, para un cálculo de la muestra cuyo resultado se provisiona por la metodología de encuestas para aplicarla de tipo semi estructurada con un nivel de confianza de 95\%, margen de error de 5\% y valores probabilísticos de ocurrencia y de no ocurrencia para un "p" y un "q" de $90 \%$ y $10 \%$ respectivamente, obtenido este por la varianza sobre una prueba piloto sobre 30 empresarios ubicados en la zona industrial y zona franca donde más converge el tema central de la investigación. Se efectuó en ellos un muestreo aleatorio simple para un desarrollo de encuetas en 184 clientes de personas que han accedido a línea de crédito compra de cartera. Por ende, la población objetivo desde la encuesta fueron, ciento ochenta y cuatreo (184) personas vinculadas en el sistema financiero como bancarizados; se entrevistaron cuatro (04) directores de oficina quienes apoyaron en la descripción del servicio con oportunidad a sobre lo que se pretendía en los objetivos de la investigación.

\section{Resultados y Discusión}

\section{Gráfica 1. Interpretación sobre el comportamiento en la Oferta de un crédito con respecto a su accesibilidad.}

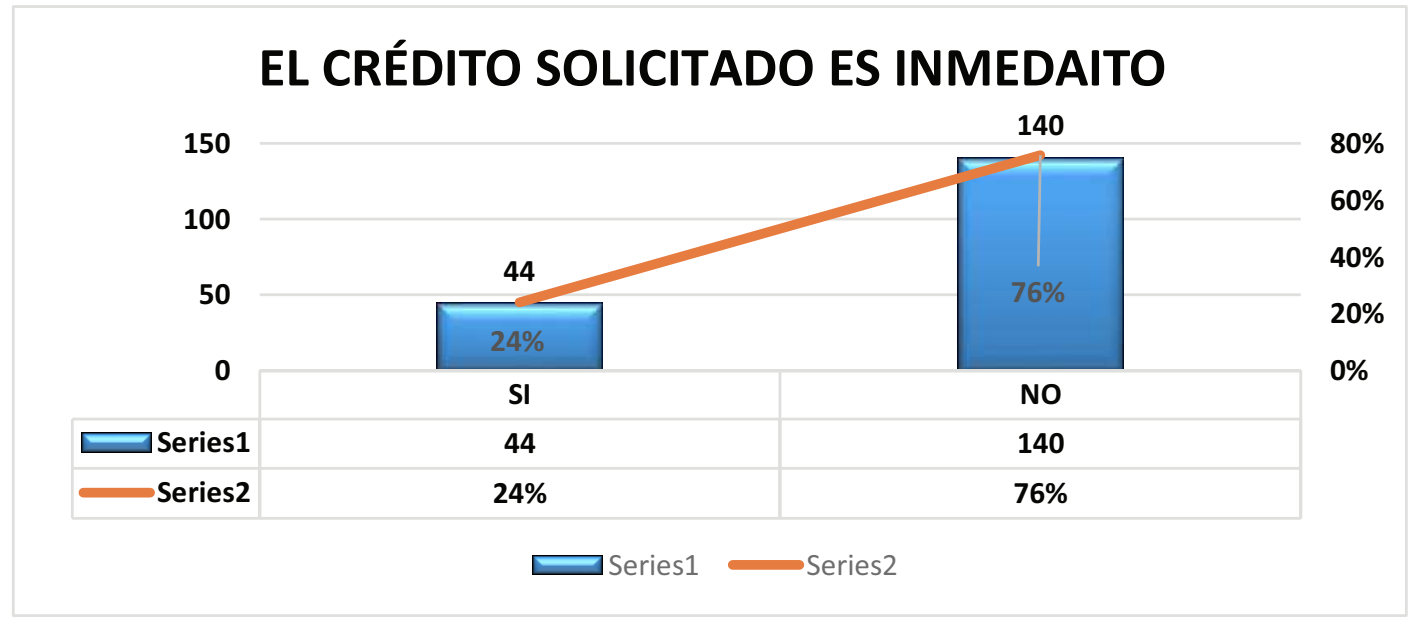

Fuente: Elaboración Propia 
En lo que respecta a la oferta que le hace una entidad bancaria para la compra de cartera respondieron las personas que sí acceden a él de manera inmediata en un 24\% y de manera negativa el $76 \%$.

Gráfica 2. Análisis financiero con relación a las tasas que le ofrecen

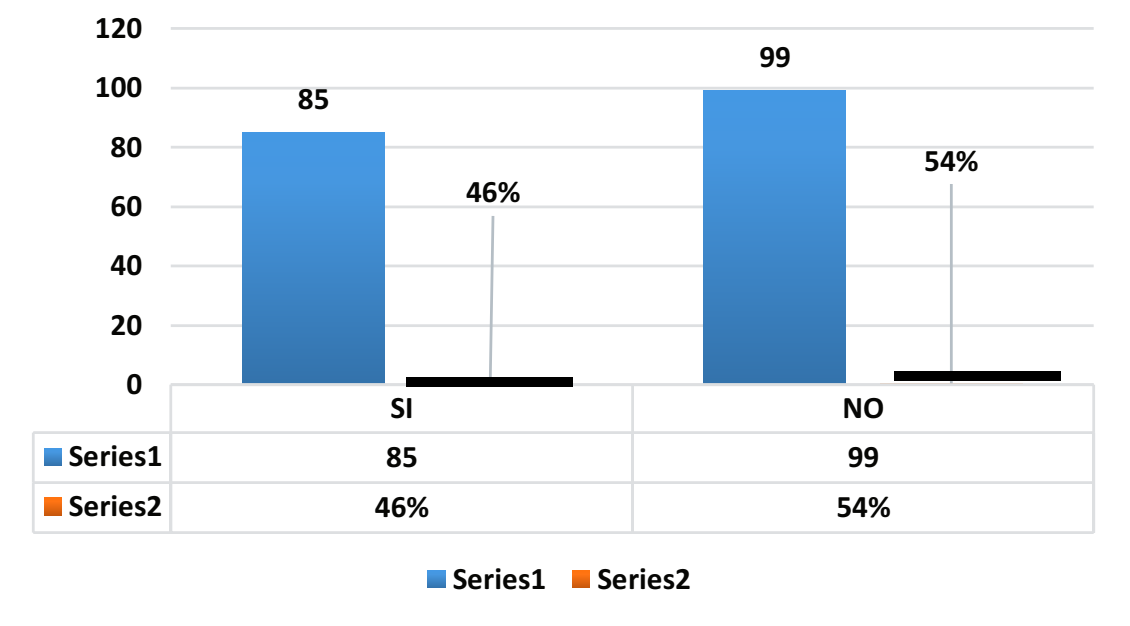

Fuente: Elaboración Propia

Con respecto al que sí en realidad les prestan atención sobre las tasas de interés que se ofertan en la compra de cartera; el 46\% manifiesta que sí lo que hace, mientras en 54\% no lo consulta o le es indiferente.

Gráfica 3. Bondades al cliente por los Bancos en el negocio Compra de cartera.

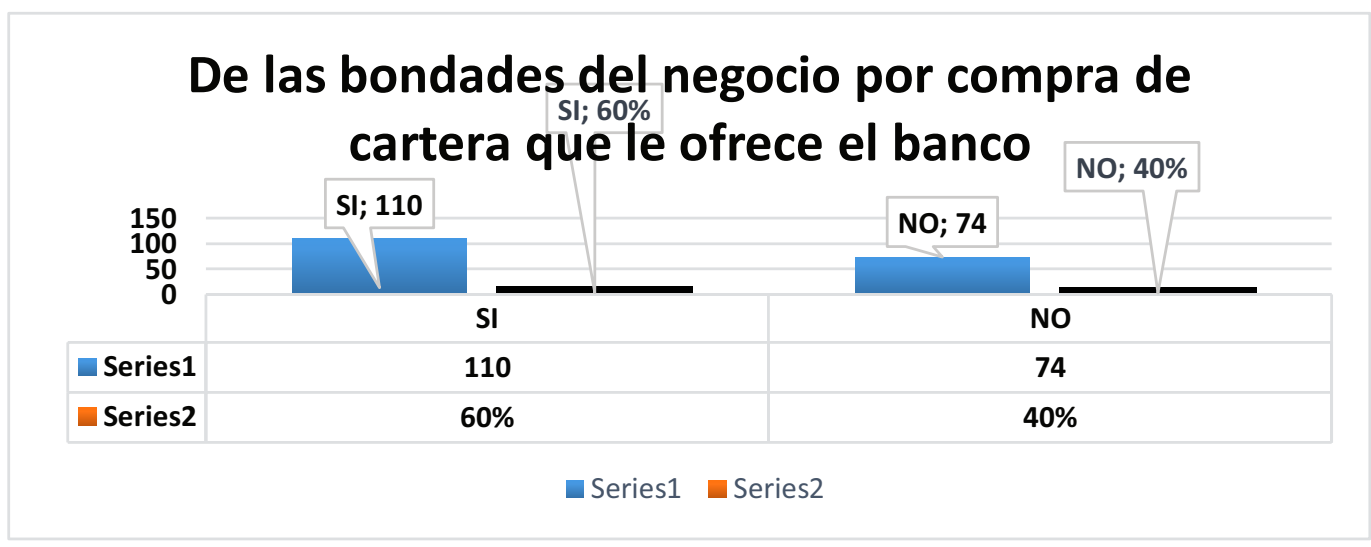

\section{Fuente: Elaboración Propia}

El $60 \%$ de los encuestados, manifestaron que les queda siempre claro sobre las bondades del negocio por compra de cartera que le ofrece el banco, en especial en los tiempos que difiere su 
REVISTA INNOVA ITFIP, 7 (1). 58-77. DIC. 2020

nuevo plan de pagos; el 40\% no tiene claro los tiempos en que se les difiere el nuevo plan de pagos y mucho menos sabe si en verdad podrían ser bondades o no.

\section{Gráfica 4. Cargos adicionales en la compra de Cartera}

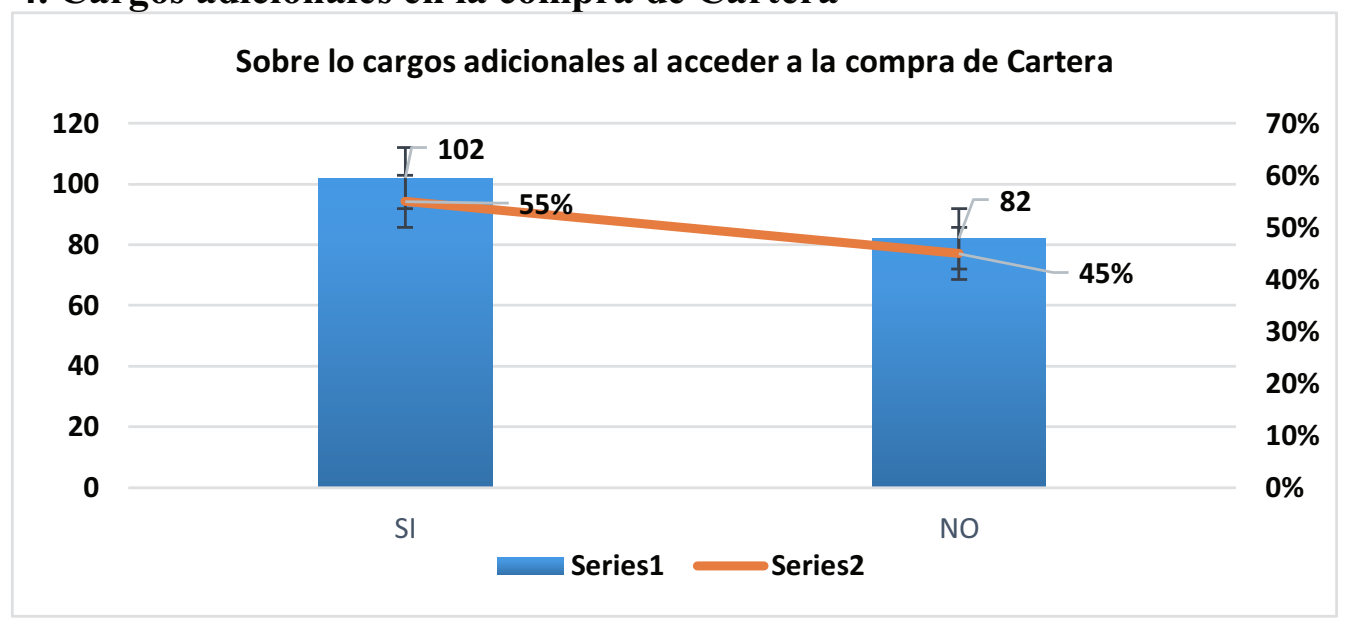

Fuente: Elaboración Propia

El 55\% de los ciudadanos encuestados manifestaron que, si conocen de los cargos adicionales que se les cobra para empezar a analizar la posibilidad de obtener un crédito, mientras que el $45 \%$ no dimensionan dichos cargos, incluyendo las consultas a las centrales de riesgo, como pagos de seguros.

Gráfica 5. Lectura de contratos de compra de cartera.

No leen las condicones de los nuevos créditos en la compra de cartera

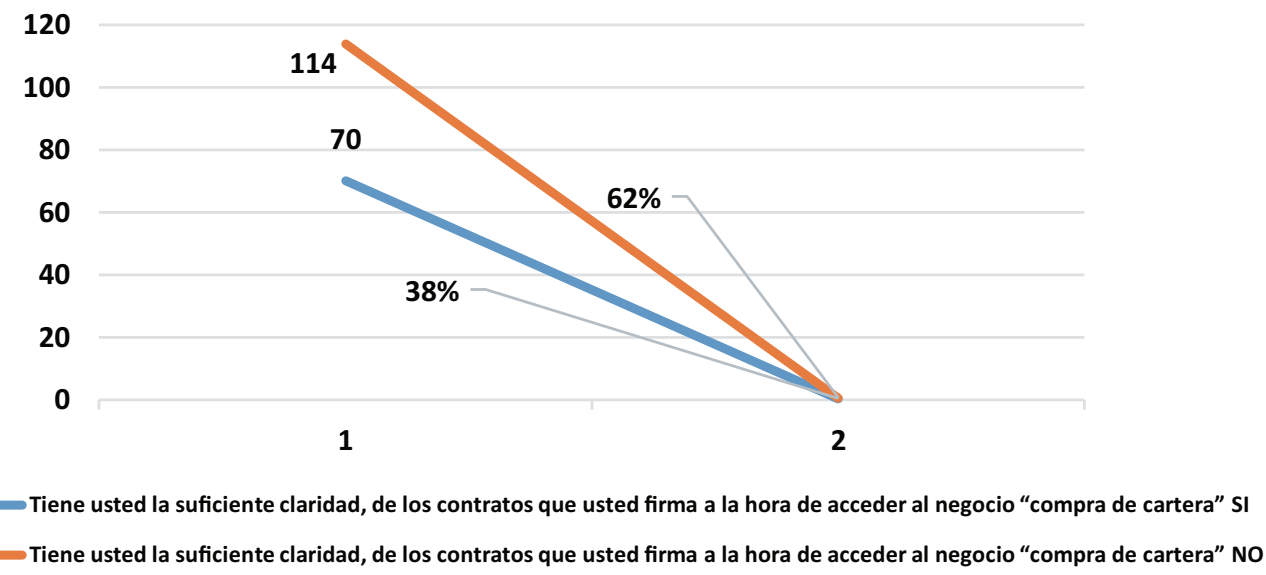

Fuente: Elaboración Propia 
El $62 \%$ de los encuestados refieren que no sabe la implicación de los formalismos firmados, no expresan ningún interés que le proviene el firmar pagares, es más no saben a qué se están refiriendo con temas de porcentajes de otros cargos adicionales.

\section{Gráfica 6. Del análisis de Riesgo Financiero, para la compra de cartera.}

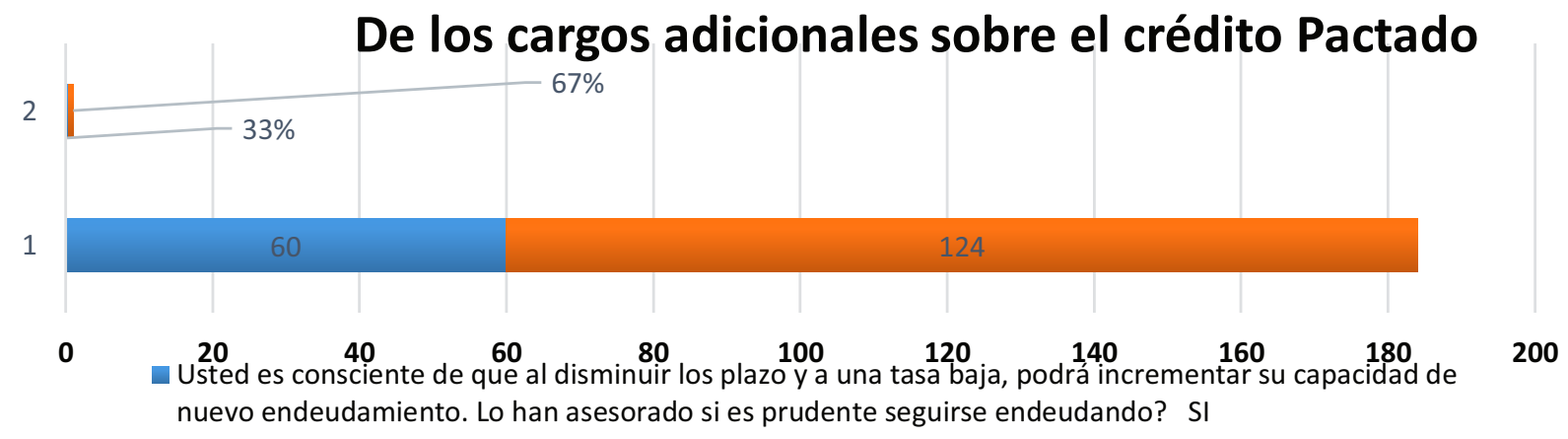

Fuente: Elaboración Propia

El 67\% de los encuestados han manifestado que, si les explican sobre el tiempo y los porcentajes de margen liquidación, pero en realidad manifiestan que lo único que les interesa es saber la fecha de desembolso. E1 33\% manifiesta si saber la nueva forma de pactar los plazos en la amortización del nuevo crédito donde inclusive también saben cuándo les explica que ampliando el plazo les libera flujo de caja, y también que la vida en amortización del crédito se extiende.

\section{Gráfica 7. Responsabilidad financiera con respecto al crédito compra de cartera}

\section{Actuación inmediatamente suguinte al desembolso del crédito}

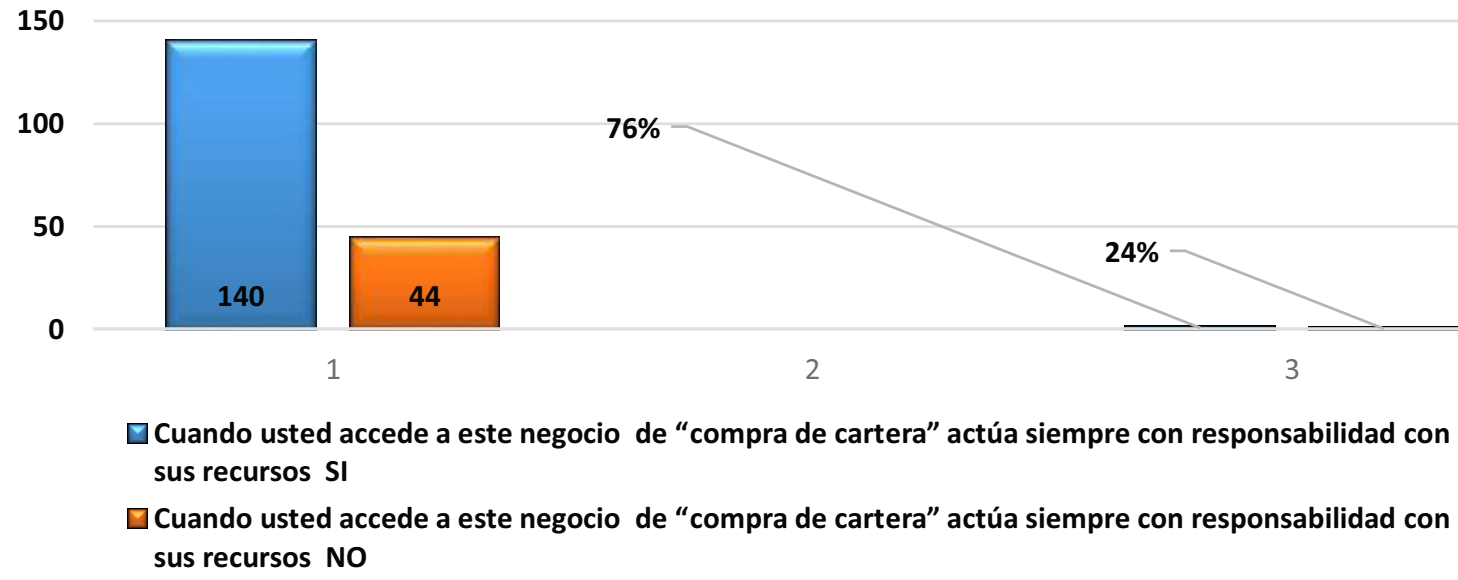

Fuente: Elaboración Propia 
REVISTA INNOVA ITFIP, 7 (1). 58-77. DIC. 2020

El 76\% de los encuestados argumentan que cuando acceden al negocio de "compra de cartera" actúa siempre con responsabilidad con sus recursos (ejemplo: devuelve las tarjetas de crédito o las sigue manejando, pero de manera más organizada como difiriendo cuotas de compras pequeñas a una sola cuota, transa endosos de cheques con las entidades a las que les debe, y sigue pagando créditos con la oportunidad de trabajar el capital).

\section{Gráfica 8. Implicación económica Regional en el Negocio " Compra de Cartera".}

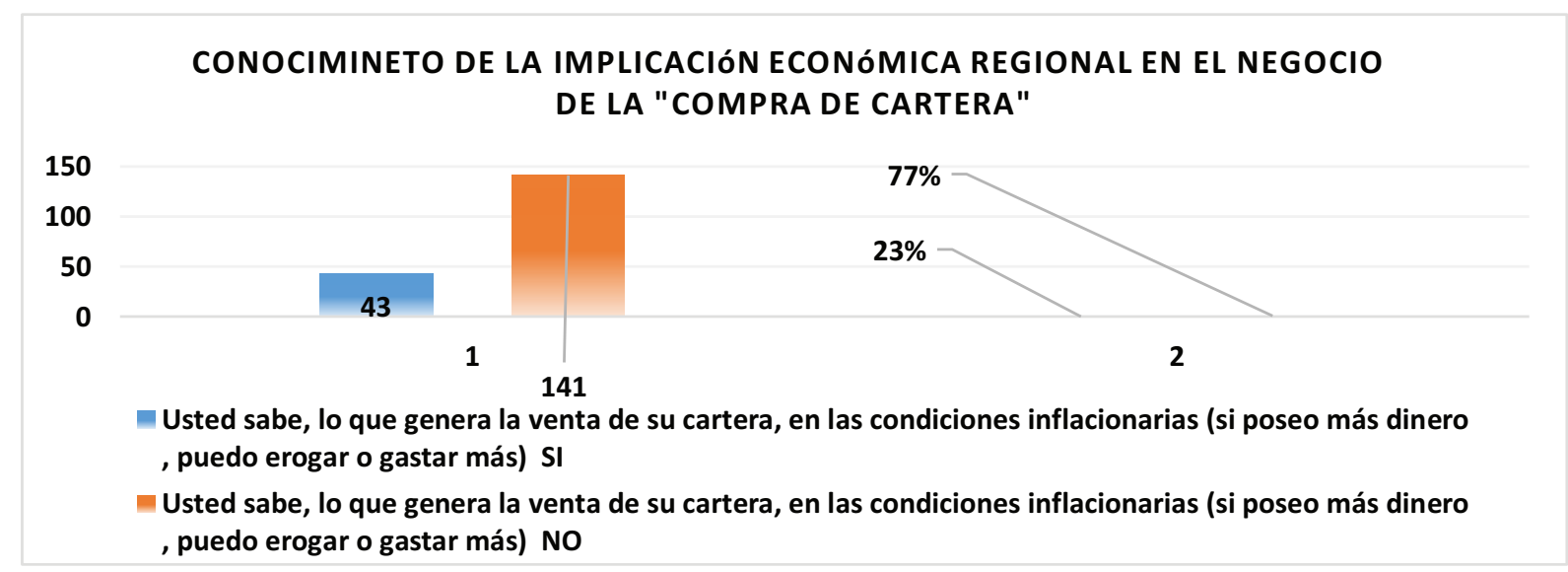

Fuente: Elaboración Propia

En esta pregunta el $77 \%$ de los encuestados respondieron no saben qué implicaciones tiene el negocio de la compra de cartera en una economía, tanto así que les parece indiferente; cuando el $23 \%$ manifiesta sí saberlo. Se observa desde esta pregunta que las personas acceden a este tipo de créditos para cubrir y poder llegar a saldar compromisos de manera más inmediata y salir de la problemática de manera mucho más rápida.

Gráfica 9. Conocimiento de cual importante es para el banco la oferta sobre el negocio "Compra de Cartera"

\section{De la oferta al negocio Compra de Cartera.}

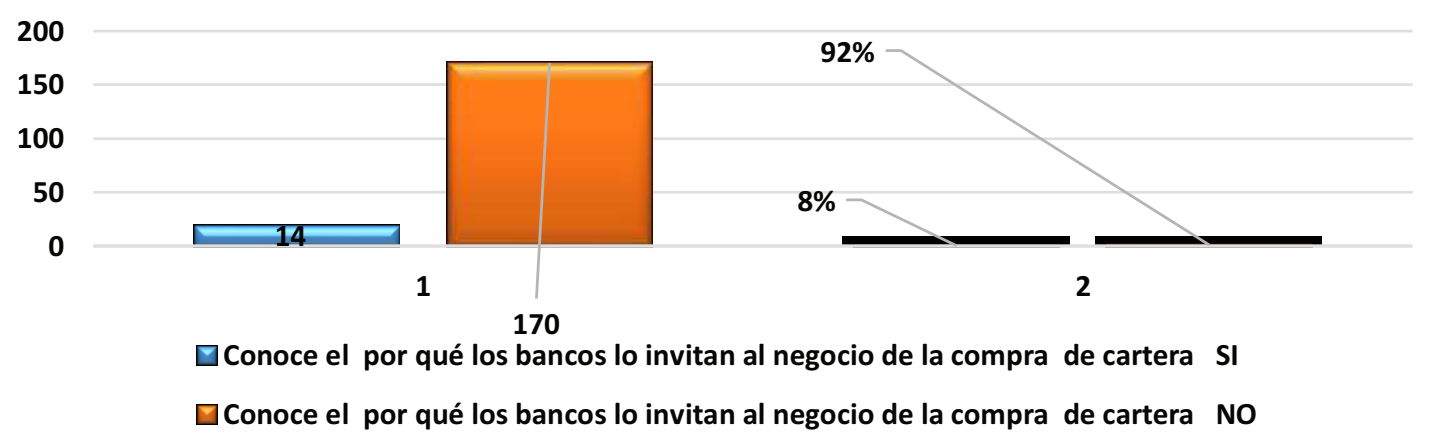

Fuente: Elaboración Propia 
Con el 92\% los encuestados respondieron que no tienen idea del por qué los bancos prestan su dinero en este tipo de crédito, el $8 \%$ de los que dijeron que $\mathrm{Si}$, indudablemente conocen que la oportunidad de los bancos está en el negocio sobre la base de la liquidez con aprovechamiento en la regulación de las tasas de interés y colocaciones a largo plazo.

\section{Síntesis del resultado desde la visión gerencial}

\section{El pensamiento de ejecutivos Bancarios y el comportamiento que incide en su portafolio de "Compra de Cartera" en la ciudad de NEIVA.}

Los clientes saben aprovechar el sector y además saben de los costos adicionales, lo que torna en ventaja es la liberación del efectivo cuando realmente lo hace bajo el saldo de los créditos; pero en la mayoría de los casos se ha venido desdibujando el comportamiento positivo de ese negocio a nivel local por cuanto algunos Bancos le apoyan en la liberación de más dinero extendiendo el plazo agregando valores adicionales por lo que significaría incrementar el cargo en intereses, en tal sentido los excedentes que el Banco les oferta lo que hacen es dejarlos en desventaja; y de otro sentido, el negocio para el banco en el portafolio de Compra de cartera en muchas ocasiones se vuelve improcedente toda vez que quien en realidad le hizo un verdadero análisis de riesgo fue la primera entidad que se lo otorgo, mientras que la otra asume lo que se analizó en primera instancia pues ya queda la existencia de una colocación. La realidad es que el cliente debería ir pagando su deuda en la entidad origen para no incurrir en cargos adicionales en intereses cuando optan en ampliar en plazos, su encarecimiento se hace evidente en la nueva amortización del crédito por cuanto en realidad se hace es un traslado de deuda.

\section{Gerencia Bancolombia}

En la ciudad de Neiva, Bancolombia nos informa en este análisis que es una entidad que brinda fidelidad a los clientes, y asesoran el verdadero comportamiento fin anciero sobre dicho traslado de cuentas de un Banco a otro. Y por ende es uno de los pocos Bancos en la ciudad que no tienen como negocio primario ese tipo de portafolio.

Bancolombia cree que la ética del negocio debe ser centrada en la entidad original que deposito un trabajo en el análisis de sus manejos financieros y que indudablemente sabe de sus alcances financieros.

De otro lado, es muy preciso decir que los Bancos en el (...) canibalismo financiero (...) llegan sobre el cliente manifestando apoyarlo liberando su efectivo que indudablemente lo hacen. Lo que preocupa es que lo persuaden para que tome otros productos con ellos toda vez que pueden tener capacidad de pago sobre el dinero o efectivo liberado, entonces llegan a obtener tarjetas de crédito, u otros productos que reitero lo hacen sobre endeudarse y llegar a transformarlo en un mal cliente e incluso con reportes en las centrales de riesgo donde en últimas debe renegociar la deuda y volverse cada vez más improcedente en el sistema financiero. 
REVISTA INNOVA ITFIP, 7 (1). 58-77. DIC. 2020

Tanto así, que Bancolombia venía trabajando antes de la Circular externa 026 del 29 de septiembre de 2017, de la Superfinanciera donde fija las condiciones para que los morosos puedan renegociar sus deudas con un modelo propio pero que hoy por hoy los han llevado a involucrarse sobre esta nueva conducta para mejorar más que con la misma venta de su cartera. Es tan delicada la situación del deudor hoy en día, que si bien le mejoran extendiendo su plazo y dándole liquidez con el primer mes de mora serán reportados y pasan de calificación de "C" a "D" con un solo pago. En un afán de obtener liquidez los clientes recurren a esos Bancos, e inclusive la irresponsabilidad de muchos de estos colocan recursos al público e incluso sin mediar garantías; por tal motivo hoy por hoy tienen carteras tan altas que son casi irrecuperables y precisamente en ese portafolio de "Compra de cartera".

El Gerente de Bancolombia oficina Ceibas Neiva, Doctor Joaquín Alberto Álvarez Rojas manifiesta que esta entidad si apoya a sus clientes en la liberación de efectivo no precisamente con ese negocio, le da la oportunidad de mejorar su liquidez con el producto sobre el cual ha tenido dificultad, pero procura en no comprometer amparos de los regulares o malos comportamientos de otros productos heredados de otras entidades colegas. En la posición que está Bancolombia se observa que no es uno de los mejores negocios para la banca hoy en día, para el cliente en la liquidez inmediata, pero a largo plazo la amortización con esa extensión de tiempos donde el dinero en tiempo futuro se hace más costoso.

\section{Gerencia Av Villas}

El banco Av Villas por intermedio de su Gerente Heiner Yasno Campo de la oficina centro de la Ciudad de Neiva también señala una situación similar, pero defiende la idea de que la oportunidad de tener efectivo brinda la posibilidad de invertir en el corto plazo. Desde luego en medio de una cultura de una verdadera visión de crecimiento en el mundo de los negocios donde allí mejora sus costos financieros y flujos de caja. Ahora bien, si el cliente es uno de los que desea que se le compre cartera de un crédito de consumo y también hipotecario se les asesora de acuerdo a su capacidad de pago en muchos casos indicarle que baje el tiempo para ahorrar recurso producto de los intereses a cobrar y así puedan liberarse de una deuda que en muchas ocasiones no valió la pena dejarlas a tan largo plazo; en lo que respecta a las desventajas se tiene que para el cliente le afecta en el inicio de un nuevo crédito perjudicándolo por los intereses ya pagados al inicio, que son los recursos que primero libera sin afectar el capital, para el caso de la ciudad de Neiva esta conducta en la que de paradójicamente las personas están accediendo producto de su afán al no ver su flujo de caja libre.

\section{Dirección Davivienda}

Un análisis expedito de la Doctora Erika Sánchez, Directora de Davivienda de la oficina Ceibas Neiva, nos ilustra que para esta entidad en la ciudad se les ha convertido una ventaja el negocio por que han aumentado los saldos de colocación, cumpliendo con los indicadores propuestos para el banco demostrando la competencia sobre las metas establecidas por ende 
reflejando el mejoramiento en las Utilidades. De otro lado, afirma que para el clien te lo que en realidad lo beneficia es solamente en lo que respecta en su flujo de caja. La Doctora Erika, analiza que las desventajas para el banco es que los saldo se disminuyen cuando un cliente sale de su portafolio o portafolios que ligado a ello es la merma de utilidades por la misma afectación de dichas colocaciones. Y desventajas para el cliente que, si no manejan el mismo tiempo, su nivel de pérdida del dinero en el tiempo se encarecería por cuanto iniciarían con un nuevo crédito.

\section{Gerencia Banco Occidente}

El Doctor Fabián Fidel Varón Vergel, en calidad de Gerente de Relación - Segmento Preferente Vicepresidente de Personas del Banco de Occidente; indica que la fidelidad del Banco de Occidente esta de la mano con la fidelidad del cliente y por eso en la dinámica y comportamiento mismo de ese portafolio se asesorará. Para que exista equilibrio en las ventajas para el cliente como para el banco. En este momento se revela las desventajas solo cuando el cliente deja de pagar sobre el producto financiero donde se podrá ver afectado con reportes en las centrales de riesgo por demora en pagos y con cargos adicionales de intereses; y que, para el banco, por la cartera que se incrementa en la colocación establecida en tal portafolio, situación que, para el caso de esta oficina, no se presenta en gran proporción por la forma selectiva de escoger nuevamente clientes en la ciudad de Neiva.

\section{Gerente Banco Caja Social}

Por su parte el Doctor Javier Ahumada, en calidad de Gerente el banco Caja Social oficina principal de Neiva, se obtiene como ventaja para el banco la posibilidad de tener clientes bien calificados en este tipo de portafolio incrementando el saldo de cartera, la calidad de cartera ganando participación en el mercado; como desventaja, se presenta en clientes no regulares e impuntuales a la hora del pago reducción del ingreso por reducción de tasa situación dada para el banco, para el cliente la modificación en la calificación en calidad de cliente. De manera indudable quien responde bien a las bondades de este crédito (...) libre destinación compra de cartera (...) le ira bien en su manejo futuro de productos financieros; en este momento Banco Caja Social tiene un balance positivo en este portafolio en particular.

\section{Análisis del sector con respecto al portafolio desde los resultados}

Los estudios técnicos, la gestión profesional y el desarrollo en la búsqueda de buenos clientes han hecho de las competencias de los gerentes toda una estrategia, lograda desde la literatura de grandes expertos inclusive nacionales conocedores de entornos financieros que de manera sistemática y organizada plasmaron sus teorías en la búsqueda de mejor colocación, esas guías que desde modelos de análisis de cartera de difícil cobro como es el Log- log hasta los más sencillos como los Z-Score llevan a minimizar los riesgos en este tipo de portafolios. Ahora desde la mirada de los clientes que son muchos persuadidos, otros nuevamente analizados y que terminan en créditos en las nuevas entidades bancarias con alternativas de solución en su problema de liquidez, de esa gestión empresarial desde la visión de los Banqueros con créditos en el portafolio "compra 
REVISTA INNOVA ITFIP, 7 (1). 58-77. DIC. 2020

de cartera" los deudores llegan también con posibilidad de tener éxito en el sentido de mejorar la solvencia económica.

Con un trabajo mancomunado y no ajeno en esa participación de colaboradores analistas, subdirectivas y demás funcionarios deben apoyar al consultado para que una vez adjudicado su crédito permanezca en equilibrio financiero con dicho portafolio, cuando el cliente queda asesorado con la ética de los bancos desde sus analistas hasta la vinculación con la directrices de la línea gerencial o directiva debe mejorar en adelante los flujos de caja, haciendo de la empresa flujos de efectivo y Estados Financieros positivos.

Las tasas pactadas, los plazos adjudicados son los que ayudan a generar la confianza para minimizar la incertidumbre y el riesgo sobre el manejo del circulante en primera instancia para las calidades de clientes, pero en segunda instancia por ende mejoraría la calificación de cliente inclusive en la tipología para el banco como para la central de riesgo.

En la actividad de este tipo de negocio con carácter de factoring financiero donde los activos operativos desde los NOF (Necesidades Operativos de Fondos) se hacen positivos sobre los FM (Fondos de Maniobra) recurriendo a esta posibilidad para valorar el universo de los activos que desde la calidad de Cash Flow pasaron a la operatividad con el mejoramiento del volumen de la liquidez. Es entonces, que el negocio de la compra de cartera bien manejada fundamenta el principio de cualquier objetivo empresarial que es el de mejorar la inversión ante la liberación de más efectivo en razón de que dicho circulante recuperable lo retornemos en la sostenibilidad financiera.

Aquella percepción del cliente desde su entorno financiero, cuando el banco hace su ofrecimiento, refieren un autoanálisis para tomar sus decisiones desde su análisis en la nueva amortización y toda vez que han accedido, manifiestan las bondades que las gerencias explican llegando al gana gana del tercero con la entidad prestamista y así garantizar el cumplimiento ante el portafolio bancario "Compra de cartera". Aun sabiendo de los cargos adicionales a los que están sujetos, deciden continuar con el acceder al negocio buscando exclusivamente la liquidez y la liberación de efectivo. Los clientes una vez más, asesorados por esta nueva entidad, se sinceraron manifestando que, confían en las gerencias sin conocer muy bien las minutas o contratos; sin la absoluta certeza de los verdaderos comportamientos en los plazos y tasas se sienten satisfechos en la liberación del cash flow sin primar la información explicita del valor de la deuda en el futuro.

Los clientes recuperan capacidades de pago, mejoran la responsabilidad sobre el cumplimiento de los compromisos a los nuevos créditos. Pese a ese positivo pago oportuno y por su liberación del efectivo en el corto plazo se les hace indiferente las implicaciones económicas locales, el cliente piensa en su habilidad comercial lograda por consiguiente pierde el interés además de las relaciones financieras y comerciales con las entidades donde origino su actividad crediticia. 
En últimas en la ciudad de Neiva quien entra en una buena cultura del manejo del circulante puede surgir en su negocio y mejorar la inversión, los clientes no se interesan tan siquiera del buen negocio que también lo es para el banco; no dimensionan ni les interesa cuánto gana un banco siendo usted uno más de sus clientes, ese $92 \%$ de desinteresados por conocer lo que implica usted para el banco solo se centran en mejorar las conductas operativas de sus nuevos créditos y verdaderos cumplimientos con liberación de efectivo para surgir en inversión.

\section{DOFA para el banco}

\section{Debilidad}

Por la mala asesoría comercial se termina negociando carteras de clientes no favorables por mala cultura de pago.

Se genera expectativas de pronto pago en algunos clientes y desde aspectos contrarios se observan clientes que comienzan a tener atraso en pagos de las cuotas.

\section{Oportunidad}

Se hacen a clientes potencialmente buenos, cuando se negocia a una buena tasa.

Se vincula la acción positiva cuando el banco pacta largos plazos en la negociación.

Venden nuevos portafolios y mejorar la captación de recurso producto de la liberación de efectivo y presunta liquidez.

\section{Fortaleza}

Categoriza el posicionamiento de Colocación del efectivo.

Busca fidelizarse como banco Triple AAA en excelentes dinámicas de colocación y captación.

\section{Amenaza}

Los bancos en la ciudad de Neiva con el propósito de tener más clientes generan una competencia sobre peleas en la oferta del portafolio.

Los niveles de riesgo se elevan porque son clientes que vienen de ser analizados por centrales propias para la medición de los mismos.

\section{Recomendaciones}

Para la ciudad de Neiva se tiene que las personas tanto naturales como jurídicas han accedido a diferentes portafolios de las entidades bancarias tanto en líneas de crédito de libre destinación, como crédito hipotecario, de vehículos entre otros. Lo que ha significado una actividad importante en aspectos de colocación para las entidades bancarias y en este orden de ideas con una observación sobre los comportamientos deficitarios de cartera, con apreciaciones de los mismos deudores 
REVISTA INNOVA ITFIP, 7 (1). 58-77. DIC. 2020

informan de los atrasos de los respectivos pagos de créditos. Esta situación lo que debe analizar el cliente es que debe tener una mejor planeación a la hora de recurrir a los créditos gestionados.

La capacidad de deuda se ha desbordado y las entidades financieras son igualmente responsables del incremento de su cartera. Las gerencias, los directores, hasta sus asesores han llevado a entregar los diferentes portafolios con libertades que inclusive los mismos clientes no miden y deciden tomarlos por la facilidad de la consecución de recursos, donde a tiempo futuro se hacen impagables. Se debe establecer desde las calidades gerenciales las posibilidades de organizar verdaderas asesorías para no incrementar eventos inclusive inflacionarios por liberación de efectivo.

Así mismo, generar una cultura a los que en realidad no saben invertir, con la oportunidad de liberar efectivo, toda vez, que su nivel de liquidez le permite acceder al portafolio que muchos bancos le ofertan para comprar su cartera, la colocación de recursos a terceros y la elasticidad de tiempos con ofertas en sus tasas que dan la factibilidad de poder acceder a este nuevo negocio.

Se plantea desde la política institucional que el producto de acceso a la compra de cartera sea un beneficio y que se logre asesorar para que consigan la liberación del efectivo.

\section{Conclusiones}

Las gerencias deben dinamizar sus aspectos de mejora continua en la Colocación y estrategas a la hora de captar, el comportamiento de la cartera en la ciudad de Neiva ha venido siendo un negocio rentable para muchas de las organizaciones en el sector financiero, a tal punto que viene revelando su desarrollo empresarial como entidad Bancaria y que por la calidad de eses Gerencias, Direcciones en la ciudad de Neiva se compite para Colocar desde el producto un portafolio atractivo como lo es la " Compra de Cartera".

Pese a que se han hecho ejercicios de asesoría financiera, los clientes por los niveles complejos del entendimiento de la matemática financiera terminan creyendo en la ética de los Gerentes y directores, pero también el aspecto de la responsabilidad financiera debe partir del conocer aspectos tan trascendentales en la economía como lo es en la propia educación y formación financiera.

Cuando se logra tener el beneficio financiero, pocas empresas con el juicio de llevar bien sus finanzas llegan al éxito comercial en razón de la liberación de liquidez, pero más con la propiedad y la certeza de realizar inversión. Por tal razón siempre se busca entonces que encontrar un equilibrio del beneficio en función de la responsabilidad de pagos y no por tanto motivar los efectos inflacionarios de la ciudad.

Así las cosas, una vez definida las debilidades, las oportunidades, las fortalezas, y las amenazas tanto para el cliente como para el banco lo que se espera es que mediante un análisis 
minucioso se pueda dejar claro que en todo negocio existen niveles de riesgo y una vez conocidos con detalle los aciertos y desacierto dichos clientes puedan tomar las mejores decisiones.

La compra de cartera si bien es cierto es un crédito con características similares de libre destinación, en el presente se ha convertido fuera de su interés en la colocación de efectivo una herramienta para que empresarios y terceros liberen efectivo para poder cumplir con deuda a más corto plazo con tasas adecuadas. En este orden de ideas, lo que se puede observar es que, en realidad los clientes buscan y hallan es circulante libre donde dicho recurso lo utilizan en nuevas erogaciones más que en inversiones, situación que lo perjudica en la calificación y en reportes a las centrales de riesgo.

\section{Referencias}

ABC, D. (2017). Obtenido de https://www.definicionabc.com/economia/venta-a-credito.php

Agudelo, N. (1985). Derecho Penal. Obtenido de http://cedpal.unigoettingen.de/data/documentacion/nuevo_foro_penal/NFP28.pdf

Asobancaria. (02 de julio de 2012). ¿ Qué es la compra de cartera? Obtenido de http://www.asobancaria.com/sabermassermas/que-es-la-compra-de-cartera/

AvaTrade, B. W . (2014). AvaTrade compra cartera de clientes de agente australiano. Regional Business News.

Chile, A. S. (Abril 2012). EL INFLUJO DE CARTERA VENCIDA COMO MEDIDA. Relevista de Análisis Económico, Vol. 27,, pp. 27-54 .

Colombia, C. d. (17 de Julio de 2008). LEY 1231 DE 2008. Colombia.

Colombia, C. d. (24 de Julio de 2009). Ley 1340. Colombia.

Colombia, C. d. (13 de julio de 2009). por la cual se regulan los principios y normas de contabilidad e información financiera y de aseguramiento de información aceptados en Colombia, se señalan las autoridades competentes, el procedimiento para su expedición y se determinan las entidades resp. Colombia.

Colombia, C. d. (01 de Febrero de 2016). Colombia.

Colombia, C. d. (7 de Julio de 2016). Ley 1793 . Colombia.

Colombia, S. F. (s.f.).

Constitucional, C. (2012).

Constitucional, C. (2013). Obtenido de http://www.corteconstitucional.gov.co/RELATORIA/2013/C-313-13.htm 
REVISTA INNOVA ITFIP, 7 (1). 58-77. DIC. 2020

Corrales, L. H. (2005). DESARROLLO DE UNA METODOLOGÍA PROPIA DE ANÁLISIS DE CRÉDITO EMPRESARIAL EN UNA ENTIDAD FINANCIERA. Scielo.

Economía, G. E. (2009). Crédito. Obtenido de http://www.economia48.com/spa/d/credito/credito.htm

ELNUEVODÍA.COM, e. (25 de Noviembre de 2011). Le venderá cartera de préstamos a bancos. Obtenido de https:/www.elnuevodia.com/noticias/locales/nota/levenderacarteradeprestamosabancos$1128572 /$

González, J. (s.f.). Le vendera cartera a los Bancos . 77.

http://diccionario.leyderecho.org/ilegalidad/. (s.f.).

http://www.asobancaria.com/sabermassermas/que-es-la-compra-de-cartera/. (s.f.).

http://www.economia48.com/spa/d/credito/credito.htm . (2009).

http://www.finanzaspersonales.com.co/invierta-a-la-fija/articulo/la-compra-de-cartera-leconviene/37133. (s.f.).

http://www.secretariasenado.gov.co/index.php/leyes-y-antecedentes/antecedentes-de-ley. (s.f.).

https://www.comparaguru.com/blog/como-identificar-prestamos-fraudulentos-o-ilegales. (s.f.).

https://www.superfinanciera.gov.co/jsp/loader.jsf?1Servicio=Publicaciones\&lTipo=publicaciones $\& 1$ Funcion $=$ loadContenidoPublicacion $\&$ id $=61279$. (s.f.).

Personal, F. (2017). Obtenido de http://www.finanzaspersonales.co/invierta-a-la-fija/articulo/lacompra-de-cartera-le-conviene/37133

Personales, F. (2017). Obtenido de http://www.finanzaspersonales.co/credito/articulo/venta-decartera-la-mejor-tasa-de-interes-para-venta-de-cartera/74604

Portafolio. (2007). Atención a la Cartera.

portafolio. (08 de marzo de 2013). Endurecen las reglas para comprar cartera a terceros.

Portafolio. (27 de junio de 2017). Lo que debe tener en cuenta al solicitar una compra de cartera.

Press, F. F. (Abril de 2009). Producto Bancario. Obtenido de http://www.trl.org/YourMoney/Documents/Productos_bancarios.pdf

República, C. d. (2009). Por la cual se dictan normas en materia financiera, de seguros, del mercado de valores y otras disposiciones. Colombia.

República, C. d. (13 de Agosto de 2012). Colombia. 
Sagner, A. (2012). EL INFLUJO DE CARTERA VENCIDA COMO MEDIDA DE RIESGO DE CREDITO: ANÁLISIS Y APLICACION AL CASO DE CHILE. Scielo.

Semana. (2017). Obtenido de http://www.finanzaspersonales.com.co/invierta-a-la-fija/articulo/lacompra-de-cartera-le-conviene/37133.

Serbía, X. (s.f.). Es tiempo de revisar creencias.

Simple, E. (2016). Obtenido de https://www.economiasimple.net/glosario/colocacion

Solidaria, S. d. (09 de Julio de 2014). Reglas para la Adquisicón o venta de cartera de crédito.

Superfinanciera. (1995). Circular Externa No.100 de 1995. Obtenido de https://legislacion.vlex.com.co/vid/circular-externa-basica-contable-398711989\#section_3

Superfinanciera. (05 de Marzo de 2013). . Obtenido de https://www.superfinanciera.gov.co/publicacion/80293

Superfinanciera. (29 de Septiembre de 2017). Circular externa 026 . Colombia.

Superfinanciera. (2018). Obtenido de https://www.superfinanciera.gov.co/jsp/loader.jsf?1Servicio=Publicaciones\&lTipo=public aciones\&1Funcion=loadContenidoPublicacion\&id=61279

superintendencia Financiera. (s.f.).

Villano, F. E. (29 de Noviembre de 2013). Obtenido de https://www.icesi.edu.co/revistas/index.php/estudios gerenciales/article/view/1737/2264

Villano, F. E. (2013). Cuantificación del riesgo de incumplimiento en créditos de libre inversión: un ejercicio. Estudios Gerenciales Elsevier.

Wire, B. (2012). Torres Unidas anuncia compra de cartera de torres chilenas. 